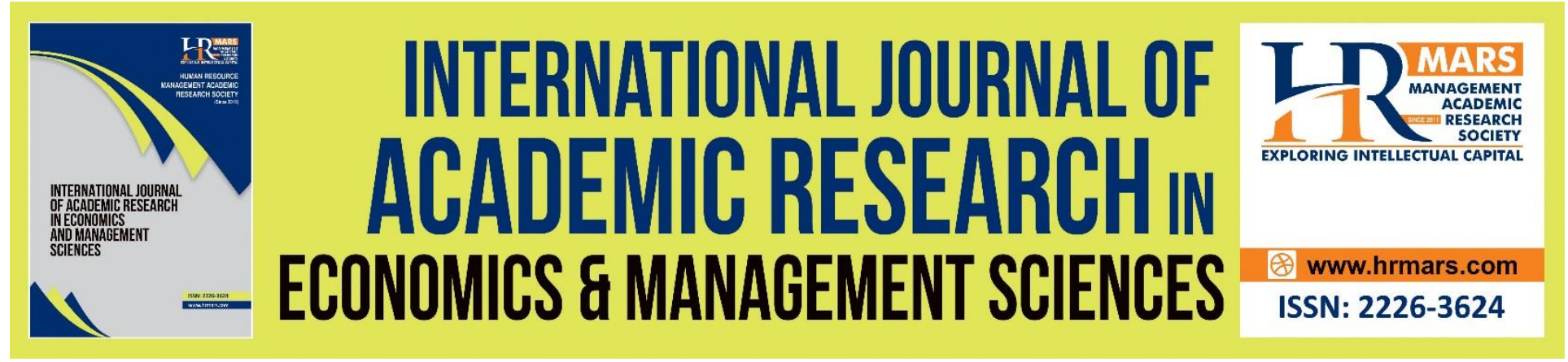

\title{
To Better Understand the Role of Emotional Processes in Decision-Making
}

Ahmed H. Alsharif, Nor Zafir Md Salleh, and Rohaizat Baharun

To Link this Article: http://dx.doi.org/10.6007/IJAREMS/v10-i2/9883 DOI:10.6007/IJAREMS/v10-i2/9883

Received: 11 April 2021, Revised: 12 May 2021, Accepted: 26 May 2021

Published Online: 26 June 2021

In-Text Citation: (Alsharif et al., 2021)

To Cite this Article: Alsharif, A. H., Salleh, N. Z. M., \& Baharun, R. (2021). To Better Understand the Role of Emotional Processes in Decision-Making. International Journal of Academic Research in Economics and Managment and Sciences, 10(2), 49-67.

Copyright: (C) 2021 The Author(s)

Published by Human Resource Management Academic Research Society (www.hrmars.com)

This article is published under the Creative Commons Attribution (CC BY 4.0) license. Anyone may reproduce, distribute, translate and create derivative works of this article (for both commercial and non-commercial purposes), subject to full attribution to the original publication and authors. The full terms of this license may be seen at: http://creativecommons.org/licences/by/4.0/legalcode

Vol. 10, No. 2, 2021, Pg. 49 - 67

http://hrmars.com/index.php/pages/detail/IJAREMS

JOURNAL HOMEPAGE

Full Terms \& Conditions of access and use can be found at http://hrmars.com/index.php/pages/detail/publication-ethics 


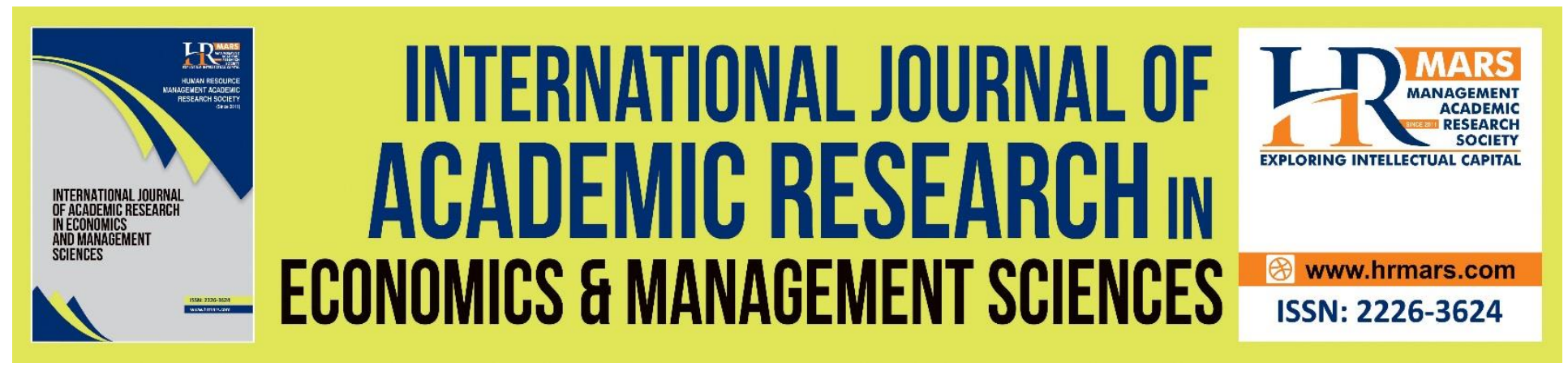

\title{
To Better Understand the Role of Emotional Processes in Decision-Making
}

\author{
Ahmed H. Alsharif, Nor Zafir Md Salleh, and Rohaizat Baharun \\ Azman Hashim International Business School (AHIBS), Universiti Teknologi Malaysia (UTM), \\ Skudai, Johor 81310, Malaysia \\ Email: ahmedalsharif07@gmail.com, zafir@utm.my, m-rohaizat@utm.my
}

\begin{abstract}
The advancement of neuroscience technology has been attracted companies' and researchers' attention. Therefore, neuromarketing studies have increased globally from about one article in 2004 to over 570 articles in 2020 based on the Web of Science database. This study aims to highlight the neuroimaging tools, the neuroanatomy of the brain, and analyses the related literature and investigates the influence of emotion on decision making via the neuromarketing approach. The finding of the research is that emotion has a substantial effect on decision-making. Where neuromarketing presents unrivalled possibilities to record the active regions in consumers' brains and provide precise data about which neurons are active when exposed to marketing stimuli.
\end{abstract}

Keywords: Neuromarketing, Neuroanatomy Brain, Neuroimaging Technology, Emotion, Decision-Making.

\section{Introduction}

Market research has been the bridge between the real consumer and those in charge since increasing in marketing activities. For them, they concentrated all their market research efforts to understand how consumers making-decisions. Therefore, many models and theories aimed to better understand the making-decision process, through qualitative or quantitative research methods. Over time, market research has been focused on qualitative methods because researchers believe maybe these methods can help to reveal consumers' perceptions and motivations about the decision-making process (Eser, Isin, \& Tolon, 2011). According to Page (2012), the consumers do not fully realize what lead them in taking a particular decision, and it has been discovered that the making-decision process is more complicated than we had realised. This leads to infer that several factors impact the making-decision process as instinctive factors which have evolved from prior experiences. In the same sense, it is challenging to forecast these instinctive factors by traditional methods; thereby, neuroscience, neuromarketing (NM), and psychology can give valuable add in determining these factors (Cherubino et al., 2019). 
Often, what we think we want has little or no bearing on the choices we actually make (Boksem \& Smidts, 2015). This also leads to infer that the decision-making process is not only relying on economic or rational factors but also interactive with emotional and cognitive processes, environment, and social factors (Vermaak \& de Klerk, 2017). Therefore, there are essential factors which are playing a vital role in decision-making processes such as emotions. That is the reason for orienting towards neuromarketing studies (Agarwal, 2015; Hu \& Nasiry, 2018). By using neuroscience tools, researchers and scientists can better understand the usual mismatches between consumers' thoughts and their actions (Jordão, Souza, Oliveira, \& Giraldi, 2017).

Ale Smidts is the first researcher who coined the term "Neuromarketing" which refers to the use of neuroscience technologies in the marketing discipline in 2002 (Ulman, Cakar, \& Yildiz, 2015). At that time, NM became known to the whole world in 2002 through the Bright House company in the USA when it has released the first report of establishing a department for using functional magnetic resonance imaging (fMRI) for conducting marketing research (Fortunato, Giraldi, \& Oliveira, 2014). NM is derived from three main fields such as neuroscience, psychology, and marketing (Javor, Koller, Lee, Chamberlain, \& Ransmayr, 2013; Vlăsceanu Sebastian, 2014). Although the term "neuromarketing" appeared in 2002, the first official article has been published in 2004 by McClure et al. (2004). Wherein the recent trends show that NM studies have been increased globally from about one article in 2004 to over 570 articles in 2020 based on the Web of Science (WoS) database (Figure 1). This trend has attracted the big companies which have the instruments and power to use NM tools (Alsharif, Salleh, \& Baharun, 2020).

The purpose of NM is to study unconscious consumer behaviours, preferences, and buying decision processes (Isa, Mansor, \& Razali, 2019). Consequently, NM has contributed to the development of marketing by explaining how unconscious responses such as emotion can affect consumer's perception and decision-making processes (Mileti, Guido, \& Prete, 2016). Since the nature of the NM provides more precise information to answer the marketing questions about the unconscious consumer's behaviour toward brands, advertisings, and decision-making processes which is impossible by traditional marketing methods (Kenning \& Linzmajer, 2011).

Different from review papers related to NM, in terms, this study discusses the NM techniques and throws light on the human's brain neuroanatomy, such as the neocortex brain, limbic brain, and reptilian brain. The main objective of this study is to provide an overview of current state-of-the-art NM practices and strategies, alongside discuss the vital role of emotion in decision-making. To this end, this study tries to combine as many directions as possible. Popular research topics are investigated deeply based on their respective sub-domains to achieve a precise, concrete, and concise conclusion. The key contributions of this study are summarised as follows.

- Presents an overview of popular research topics on NM, including techniques, evolution in the main areas of application, challenges, and ethical issues.

- Illustrates the anatomy of the brain and the component and functions of each one, also the vital role of emotion in influencing decision-making processes.

- Provides new references to other researchers who need insights into enabling NM techniques.

This article is organised as follows. Sections 2 illustrates affective neuroscience (e.g., dimensions of emotion, motivation, and the somatic sign hypothesis). Section 3 presents the 
triune of the human brain. So, section 4 presents an overview of the neuromarketing tools used in marketing research. While section 5 presents the benefits of neuromarketing tools in marketing research. Section 6. discusses the ethical and challenging issues in applying NM. Finally, Section 7 concludes the work and future trends.

\section{Affective Neuroscience}

Feelings are considered as the result of conscious emotional status (e.g., level of pleasure or unpleasure). In contrast, emotions are the unconscious emotional reactions (e.g., as approaching and avoidance behaviour), there are several techniques to measure emotion and feeling, as depicted in (Figure 2) (Scherer, 2005). Emotion plays a vital role in the consumer's behaviour (Ahmed H. Alsharif et al., 2021; T. Ramsoy, 2014). Emotions and feelings can be used by marketers and advertisers as stimuli in order to attract the consumers' attention and influencing their behaviours. Where negative emotions can enhance avoidance behaviour, whereas positive emotions can enhance approaching behaviour. In other words, identifying the emotional status of the consumers by marketers give them leverage to better understanding consumers' opinions about products before launching; thereby, it helps them to measure the percentage of satisfaction in the market (Montazeribarforoushi, Keshavarzsaleh, \& Rams $\varnothing y$, 2017). Emotions refer to bodily responses such as increased heart rate in a particular situation; feelings refer to the psychological aspects such as feelings of being afraid and so on. Simply, the difference between emotions and feelings is in terms of physiological versus psychological aspects respectively (Alsharif et al., 2021; LeDoux \& Brown, 2017).

Below it will be discussed emotion because of our study about unconscious processes. Although emotions are sometimes annoying, they are extremely important to consumers' behaviours, and they are not able to evaluate their options without them. The concept of emotion has been described in various ways by numerous authors, according to the theory they follow. Frijda (1987) defined emotions as the individual's tendency to create, maintain, or terminate a relationship with the environment or with others. As well, according to Antonio $R$ Damasio (2003), emotion is the set changes of the somatic and brain status as a result of the human responses based on the perceptions of humans. These definitions are still hotly debated (Adolphs \& Andler, 2018; Barrett, 2017). It can be described emotion by providing explanatory examples such as fear, anger, disgust, happiness, sadness, and so on (Thagard, 2019). The emotions correspond to a construct that the individual creates, allowing for the emotional evaluation of the event, and because of this, the basic emotions are relatively constant for each individual (Lazarus, 2006).

\section{Dimensions of Emotion}

Valence refers to the tone of emotional responses (e.g., positive or negative) produced by a stimulus or the situation that elicits individuals (Patrizia Cherubino et al., 2019), whereas, Arousal refers to the intensity of emotional responses which are commonly used to classify the different forms of emotional affect (Figure 3) (Dolcos et al., 2019). It may be high when the stimulus produces a high activation in the participation (e.g., seeing a high discount on price) or maybe low when it produces low activation (e.g., seeing expected price). Several models have affirmed valence and arousal as two dimensions of emotion (Dolcos et al., 2019). With these two dimensions, valence measures from positive to negative while emotional arousal measures from 
high to low (Posner, Russell, \& Peterson, 2005; T. Ramsoy, 2014).

In the same context, it is too difficult to separate between them because stimuli use to induce emotional valence and determine a change in emotional arousal (Lindquist, Satpute, Wager, Weber, \& Barrett, 2015). Therefore, it is important to examine the role of positive and negative stimuli in attention and the associated processes and dissociate between different levels of arousal within the emotional categories, which can be achieved (Shafer et al., 2011).

\section{Motivation}

Motivation and emotion are related to each other, where the right brain is responsible for this step to generate emotions to motivate consumers for purchasing decisions (Dolcos et al., 2019). Motivational processes play a vital role in the impact on our perception and behaviour (Luiz Pessoa, 2013). So, the market managers must well-study the consumer's motivations to orient the appropriate marketing mix toward the right target audience (Bahrabad \& Farrokhian, 2017). For instance, motivations are a more oriented goal, and it is considered a driving force to engage in the actions to satisfy our goals (Pessoa, 2009). In addition, motivation helps us understand how to adapt to the environment and know a source of benefit and harm (Dolcos et al., 2019). Therefore, when we talk about motivations, we should talk about two different motivational systems: wanting and liking. Liking is associated with a conscious hedonic experience, and it is reflected in our verbal decisions. At the same time, the wanting system is related to the unconscious. In most cases, what you want is what you like (T. Ramsoy, 2014). Accordingly, motivation, decision-making, and preference formation have been gained popularity in academic research fields (Montazeribarforoushi et al., 2017).

\section{The Somatic Sign Hypothesis}

It has proven that emotions are not against the brain, and also it is not the enemy of the brain, on the contrary, they are extremely important for the making-decision process (Antonio R. Damasio, 1994; Hammond, 2006). Damasio had been noticed from studying his patients that the patients with damage in the ventromedial prefrontal cortex (VmPFC) are not good decisionmakers, but they can hardly make personal and social decisions which reflected in their efficiency of choice and repeat the same mistakes which lead them to negative consequences (Bechara et al., 2005). It had experimented the soda drinks, concluded that people with damage in the ventromedial prefrontal cortex (VmPFC) persisted on the same choice and ignore the brand information, whereas, people without damage in the same region changed their choice to brandcued, which led to infer that the ventromedial prefrontal cortex (vmPFC) plays a significant role in making-decision processes (Deppe, Schwindt, Kugel, Plassmann, \& Kenning, 2005; Koenigs \& Tranel, 2008). Although the patients with lesions in the vmPFC were intact on standard neuropsychological tests, they have less ability to express their emotions and feelings in appropriate circumstances which led to infer Damasio's somatic hypothesis (Antonio R. Damasio, 1994; Tranel \& Damasio, 1991). It has used the term "the somatic signs" to describe the influence of emotions on the participants, assessments, decisions, which indicated that the patients with a lesion in the vmPFC of the brain are not able to make sound decisions (Antoine Bechara \& Damasio, 2005). 


\section{The Triune Brain}

First and foremost, the human brain is divided into two hemispheres (e.g., left and the right hemisphere). Additionally, the human brain represents only $2 \%$ of the body weight and consumes approximately more than $20 \%$ of the body's energy (T. Ramsoy, 2014). The human brain has divided into three main layers, namely, the neocortex (rational) brain, limbic (emotional) brain, and reptilian (primitive) brain (Figure 4) (Gani, Reza, \& Rabi, 2015). It was believed that there is a specific area in the human brain for each decision-making, such as controlling the breath. However, complex processes such as decision-making are connected with many areas in the brain, which makes it more challenging to determine (Alós-Ferrer, 2018; Senior \& Lee, 2013). It will be discussed briefly location, components, functions, and contributions of each brain layer, tabulated in Table 1.

It will be also discussed some important regions in the brain which belong to various lobes in the brain, as follows:

- Broca's region: which is located in the frontal lobe $(F L)$, helps to generate languages and speech (Zurawicki, 2010).

- Wernicke's region: it is located in the $\mathrm{FL}$, which is related to visual perception and recognition of the auditory stimuli, speech, language, and memory (Montazeribarforoushi et al., 2017).

- Somatosensory cortex: it is located in the parietal lobe (PL), which is necessary for processing sensory information (e.g., touch, vision, etc.) (Spielman, Dumper, Jenkins, Lovett, \& Perlmutter, 2014).

- Motor cortex: which is located in inferior most parts of the frontal cortex, also showing a sensory-like mapping of the body and is crucial for controlling body movements (Zurawicki, 2010).

- vmPFC: It is located at the bottom of the cerebral hemispheres in the frontal lobe. This area is receiving and sending much information, which affects several brain regions, including the amygdala; it is also associated with risk, fear, and reward processing (Motzkin, Philippi, Wolf, Baskaya, \& Koenigs, 2015), and plays a key role along with orbitofrontal cortex (OFC), in organizing emotional responses which are important in decision making (Carlson, 2012). Besides, the vmPFC and the dorsolateral prefrontal cortex (dIPFC) are playing a vital role in the execution of the choices more than OFC (Montazeribarforoushi et al., 2017).

- dIPFC: It is the topmost part of the prefrontal cortex (PFC) and involves cognitive processes (i.e., planning, cognitive flexibility, and working memory) and decisionmaking processes (Rilling, King-Casas, \& Sanfey, 2008).

- OFC: It is a medial part of the PFC and close to the amygdala (AMY) and hippocampus $(\mathrm{HC})$, related to the same functions of emotions and decision-making processes. It is highly connected with the limbic system and, as such, is connected with people's ability to make decisions relying on emotional information. Plus, it plays a key role in building social links and organizing emotions, and this region effectively integrates external and internal factors (Amthor, 2016).

- Amygdala: It has pointed out the amygdala has extremely received attention from researchers interested in understanding the biological basis for emotions (Maren, 
Phan, \& Liberzon, 2013). The AMY consists of two almond-shaped sets of neurons on either side of the thalamus at the lower end of the hippocampus. It is responsible for all types of human motivational and emotional responses, such as anger, anxiety, and even sexual responses, so it plays a crucial role in conveying comprehensive information between the neural areas. Additionally, it is also accountable for the emotional value of learning processes and memory (Amthor, 2016).

- Hippocampus: This part is essential for uniting information, including long and shortterm spatial memory. The cortical region, which surrounds the HC known as the Parahippocampal gyrus, is responsible for scene recognition, memory encoding, and restoration (Amthor, 2016).

\section{Neuromarketing Methods Used in the Marketing Research}

By neuroimaging technology, it has become possible to get the data in the form of neural signals and images from the individual's brain; thereby, they have become significant for early diagnosis (Cartocci et al., 2015), not only for marketing research (Di Flumeri et al., 2016) but also for the interactions between individuals and external environment (e.g., machines, animals, .., etc.) (Zander \& Kothe, 2011). T. Z. Ramsoy (2015) (a) neuroimaging techniques such as functional magnetic resonance imaging ( $\mathrm{fMRI})$, positron emission tomography (PET), functional nearinfrared spectroscopy (fNIRS), electroencephalography (EEG), magnetoencephalography (MEG), steady skin topography (SST), and single-photon emission tomography (SPET); (b) Physiological techniques such as the electrocardiogram (ECG), eye-tracking (ET), facial expression recognition, galvanic skin response (GSR); (c) Behavioural measurements such as self-report, questionnaires, observations (Figure 5). In the 1960s, it has been applied psychophysiological tools to measure pupil dilation of consumers by eye-tracking technique and electrodermal response (EDR) by heart rate (Wang \& Minor, 2008). But in the early 1970s, it was the "boom" by using EEG to measure the response of consumers during watching television. Thereafter, many researchers have used the EEG technique in their researches (Cherubino et al., 2019). EEG and fMRI are deemed as the most favourite tools among scientists which using different methods to measure the consumers' reactions toward marketing stimuli, i.e., advertisement (Alsharif et al., 2020; Fortunato et al., 2014; Lim, 2018).

Each tool used in neuromarketing research has advantages and disadvantages (Alsharif et al., 2021), making them more or less suitable for various research circumstances (Morin, 2011). Wherein these tools depend on temporal and spatial accuracy in recording the activity regions in the human brain to answer questions related to marketing issues (Alsharif et al., 2021; Sebastian, 2014).

\section{The Benefits of Neuroimaging Technology in Marketing Research}

Neuromarketing techniques are commonly used in the advertising realm. Wherein NM is a tool used to know how different marketing stimuli such as exposure to certain advertisements impact buying decisions (Venkatraman et al., 2015). For example, identify the negative elements in advertising which cause an individual's aversion to the products, as well as allows to determine visual and audio features and selection of appropriate media (Fugate, 2007). Plus, NM also can identify the real unfulfillment of consumer's needs; in such a way, it helps for developing more useful and pleasant products, advertisements, and satiable the actual consumer's needs and 
desires (Eser et al., 2011). According to Fortunato et al. (2014), neuromarketing's contributions often help in developing branding strategies and positioning a brand in the market. Furthermore, neuromarketing also has the ability to adjust its pricing strategy and developing brand and product. Therefore, as mentioned by Fisher, Chin, and Klitzman (2010), neuromarketing has enormous ability to determine the real marketing issue such as compulsive buying disorder (CBD). In addition, it also has the capacity to create more successful social initiatives, such as encouraging the usage of seat belts in cars (Orzan, Zara, \& Purcarea, 2012) and antismoking campaigns (Modica et al., 2018). Indeed, neuromarketing measured and examined the intensity of emotional attachments toward a brand and the effect of stimuli to be implemented on the point of sale to promote purchases (Cherubino et al., 2017). Consumers and markets have different characteristics depending on the period of time. For example, lifestyle nowadays is different from the past and, definitely, it will be different in the future. Currently, the competitive environment has increased among companies as a result of technological progress. Therefore, new challenges, opportunities, and limitations have emerged, which considerably changed the marketing management, as each company seeks to discover new methods/approaches to know what is in the consumer's mind in order to meet their needs and beat competitors.

Advances in neuroscience/neuroimaging technology have led to an increase in the number of publications about studying the human brain; thereby, getting accurate images of the human brain, which led to a better understanding of its structure and functions. Accordingly, researchers and scientists from other fields have interested in applying neuroimaging tools in their researches. For example, it has grabbed attention from huge business establishments to use these tools in their researches to dive deep into the consumer's brain to knowledge the underlying reasons for consumers' choices in order to satisfy their actual needs. Notably, by using neuroimaging tools, companies have only an opportunity to better understand the consumer's behaviour as the mechanisms of making-decision and what processes are affected makingdecision in the brain. But not as some researchers and journalists claimed that it could potentially determine the "buy button" in the consumer's brain and manipulate their brains and induce them to buy undesired the concerned companies' products or services. Admittedly, neuromarketing researches are not separate from traditional marketing researches because neuromarketing cannot alone answer the research questions but together, it is possible to answer the research questions by relying on the neuromarketing tools to knowledge the mechanisms of makingdecisions, thus, making sure of the result obtained through traditional marketing methods. Therefore, neuromarketing and traditional marketing methods complementary.

\section{Ethics and Challenges}

Actually, the significant concern for the term "Neuromarketing" has rapidly risen throughout the last decade, which led to discussing series of ethical issues not only in society but also in scientific committees, media, and press (Murphy, Illes, \& Reiner, 2008; Ulman et al., 2015). For example, when the publicity and media have reported about the potential dangers of NM regarding finding a "buy button" in the individuals' mind by advertisers and marketers (Stanton, Armstrong, \& Huettel, 2017), to analyze their private thoughts and emotions to impact on their purchasing decisions, besides manipulation of the consumers' minds (Berliñska \& Kaszycka, 2016). Indeed NM is used to create better products or ads to entice consumers but not manipulate the consumers' minds (Stanton et al., 2017). For example, companies can know their 
consumers' preferences and behaviours by NM and, thus, can provide more beneficial and profitable services and products. According to Ariely and Berns (2010), NM's application by companies concentrating on profit rather than consumers' wellbeing through harmful ads for products (e.g., tobacco, alcohol..., etc.). This may be true to some extent, the reason to indicate NM for violating ethical boundaries and breaking the consumers' trust.

In addition, many scientists and researchers have pointed out NM might threaten individuals' privacy if this technology can deal with consumer behaviour effectively and accurately (Murphy et al., 2008). But others have argued that these worries are probably premature because state-of-the-art imaging technology does not allow for precise predictions of consumers' decisions (Brammer, 2004). Thus, NM danger concerns have led several governments (e.g., France) to take some concrete procedures against rogue use of NM tools (Nemorin \& Gandy, 2017). Therefore, the ethical issues are considered the most sensitive factors that should be considered when neuro-scientists, neuro-marketers, and companies conduct their academic and commercial NM research (Pop, Dabija, \& Iorga, 2014). Thus, companies have to abide by rules and ethics issues (Arlauskaitè, Sferle, \& Arlauskaite, 2013). Plus, companies should abide by the laws and the government's declarations regarding consumers, children, and patients (UIman et al., 2015). For instance, any studies related to human research should follow the government's laws, and it must conduct a rigorous investigation after any human researches by government and company ethics committees (Moreno \& Arteaga, 2012).

In this regard, firstly, companies and organization have to focus on the orientation of the NM toward the right way by increasing the wellbeing of society and produce profitable products to satisfy the actual consumers' needs and desires; meanwhile, it should not fall into promoting harmful products such as but not limited to, tobacco, which the press and media can be exploited it to fuelling speculations and trigger aggressive attack to NM. Secondly, companies and organizations should not look at these arbitrary assumptions and continue to strive for success and stay productive. Eventually, it is hoped that all companies follow the government rules and instructions to secure the consumers' safety and privacy foremost.

\section{Conclusion and Future Trends}

Traditional marketing methods tried to understand consumer behaviour (i.e., purchasing decision-making) by using the qualitative and quantitative methods wherein consumers are consciously reporting about their experiences, thoughts, and preferences. On the opposite side of the spectrum, unconscious and subconscious processes (e.g., cognitive and affective processes) of consumer behaviour are highly unmeasured by traditional methods. Neuromarketing tools research has the potential to study the cognitive and affective processes without depending on the verbal and conscious report of consumers that have been used in marketing practices for a long time. Neuromarketing studies have become important for studying consumers behaviour in marketing practices due to the neuromarketing studies have been proven that consumers are emotional decision-makers rather than rational decision-makers as was believed for a long time in economic theory. Therefore, it has seen a growth of scholars abilities to study and explain the brain activity regions toward marketing stimuli such as advertisements and brands. Consequently, neuromarketing has been very beneficial to provide accurate information about consumer behaviours, preferences, perceptions toward marketing stimuli due to the overcome the limits that affect traditional methods in various aspects. Thus, 
neuromarketing is introduced as a revolutionary area in marketing research. In the last decade, both academia and industrial environments are immensely interested in knowing how marketing research can benefit from integrating new area into traditional methods to develop marketing research and solve the marketing issues. Therefore, this study aims to contribute the clear vision towards NM by highlighting the common neuromarketing techniques used in marketing research, the role of affective processes in influencing decision-making processes, in addition, to improve our understanding of consumer behaviour relevant to marketing.

According to the aforementioned, researchers advise integrating neuroscience methods with traditional methods to enhance the effectiveness of marketing methods. Therefore, it is better to choose the appropriate NM methods for study to answer research questions and objectives. It is also highly significant to focus on unconscious processes (e.g., emotion) to overcomes the limitations of traditional methods. Emotions and feeling are playing a central role in influencing the consumer decision-making processes which in turn lead to purchase decisions. Another intriguing point, companies, and organization have to focus on the orientation of the NM toward the right way by increasing the well-being of society and providing solutions to daily problems that faced the companies and consumers. The honest use of these instruments by scientists and researchers to clearly understand consumers, particularly their needs and motivations, allow scholars to produce valuable products to satisfy the actual consumers' needs and desires; meanwhile, not to promote harmful products, which the press and media can be exploited it to fuelling speculations about NM methods (e.g., buy button in the consumer mind, manipulate the consumer mind).

By neuromarketing researchers can know the strengths in marketing stimuli, boost and ignore the weaknesses, thereby, create effective ads and products which in turns lead to reduce the wastage of budget on advertising and products. Therefore, the companies that use NM have a potentially proactive advantage over those that cannot, or do not, use it. It is hoped that all companies follow the government rules and instructions to secure the consumers' safety and privacy foremost. Finally, the coming years will see greater collaboration between various fields (e.g., economics, neuroscience, marketing, and sociology) to describe accurate decision-making processes in real contexts.

\section{References}

Adolphs, R., \& Andler, D. (2018). Investigating emotions as functional states distinct from feelings. Emotion Review, 10(3), 191-201.

Agarwal, S. (2015). Introduction to Neuromarketing and Consumer Neuroscience. Journal of Consumer Marketing, 32(4), 302-303. doi:10.1108/jcm-08-2014-1118

Alós-Ferrer, C. (2018). A review essay on Social neuroscience: Can research on the social brain and economics inform each other? Journal of Economic Literature, 56(1), 234-264.

Alsharif, A. H., Salleh, N. M., Baharun, R., \& Yusoff, M. E. (2021). Consumer Behaviour Through Neuromarketing Approach. Journal of Contemporary Issues in Business and Government, 27(3), 344-354.

Alsharif, A. H., Salleh, N. Z. M., \& Baharun, R. (2020). Research trends of neuromarketing: A bibliometric analysis. Journal of Theoretical and Applied Information Technology, 98(15), 2948-2962. 
Alsharif, A. H., Salleh, N. Z. M., Baharun, R., Hashem, E. A. R., Mansor, A. A., Ali, J., \& Abbas, A. F. (2021). Neuroimaging Techniques in Advertising Research- Main Applications, Development, and Brain Regions and Processes. Sustainability, 13(11), 6488-6513.

Alsharif, A. H., Salleh, N. Z. M., Baharun, R., \& Safaei, M. (2020). Neuromarketing approach: An overview and future research directions. Journal of Theoretical and Applied Information Technology, 98(7), 991-1001.

Amthor, F. (2016). Neuroscience for dummies: John Wiley \& Sons.

Ariely, D., \& Berns, G. S. (2010). Neuromarketing: the hope and hype of neuroimaging in business. Nature Reviews Neuroscience, 11(4), 284-292.

Arlauskaitè, E., Sferle, A., \& Arlauskaite, E. (2013). Ethical issues in neuromarketing. Science, 311(2), 47-52.

Bahrabad, M. R., \& Farrokhian, S. (2017). The Effect of Personality on Purchase Decisions Based on New Freud's Theories and Behavioral Theory in Mashhad.

Barrett, L. F. (2017). The theory of constructed emotion: an active inference account of interoception and categorization. Social cognitive affective neuroscience, 12(1), 1-23.

Bechara, A., \& Damasio, A. R. (2005). The somatic marker hypothesis: A neural theory of economic decision. Games economic behavior, 52(2), 336-372.

Bechara, A., Damasio, H., Tranel, D., \& Damasio, A. (2005). The somatic marker hypothesis: Some questions and answers. Trends in cognitive sciences, 9(4), 159-162.

Berliñska, E., \& Kaszycka, I. (2016). Neuromarketing-chance or danger for consumers in opinion of MCSU's students. Paper presented at the Managing Innovation and Diversity in Knowledge Society Through Turbulent Time: Proceedings of the MakeLearn and TIIM Joint International Conference 2016.

Boksem, M., \& Smidts, A. (2015). Brain responses to movie trailers predict individual preferences for movies and their population-wide commercial success. Journal of Marketing Research, $52(4), 482-492$.

Brammer, M. (2004). Brain scam? Nature neuroscience, 7(10), 1015-1015.

Carlson, N. R. (2012). Physiology of behavior 11th edition: Pearson.

Cartocci, G., Maglione, A. G., Vecchiato, G., Di Flumeri, G., Colosimo, A., Scorpecci, A., ... Borghini, G. (2015). Mental workload estimations in unilateral deafened children. Paper presented at the 2015 37th Annual International Conference of the IEEE Engineering in Medicine and Biology Society (EMBC).

Cherubino, P., Caratù, M., Modica, E., Rossi, D., Trettel, A., Maglione, A. G., . . Babiloni, F. (2017). Assessing cerebral and emotional activity during the purchase of fruit and vegetable products in the supermarkets. In Neuroeconomic and Behavioral Aspects of Decision Making (pp. 293-307): Springer.

Cherubino, P., Martinez-Levy, A. C., Caratu, M., Cartocci, G., Di Flumeri, G., Modica, E., ... Trettel, A. (2019). Consumer Behaviour through the Eyes of Neurophysiological Measures: Stateof-the-Art and Future Trends. Computational Intelligence and Neuroscience, 2019. doi:10.1155/2019/1976847

Cherubino, P., Martinez-Levy, A. C., Caratu, M., Cartocci, G., Di Flumeri, G., Modica, E., ... Trettel, A. (2019). Consumer behaviour through the eyes of neurophysiological measures: State-ofthe-art and future trends. Computational Intelligence and Neuroscience. 
Damasio, A. R. (1994). Descartes\&\#39; error : emotion, reason, and the human brain: New York : G.P. Putnam, [1994] (C1994.

Damasio, A. R. (2003). Looking for Spinoza: Joy, sorrow, and the feeling brain: Houghton Mifflin Harcourt.

Deppe, M., Schwindt, W., Kugel, H., Plassmann, H., \& Kenning, P. (2005). Nonlinear responses within the medial prefrontal cortex reveal when specific implicit information influences economic decision making. Journal of neuroimaging, 15(2), 171-182.

Di Flumeri, G., Herrero, M. T., Trettel, A., Cherubino, P., Maglione, A. G., Colosimo, A., .. Babiloni, F. (2016). EEG frontal asymmetry related to pleasantness of olfactory stimuli in young subjects. In Selected Issues in Experimental Economics (pp. 373-381): Springer.

Dolcos, F., Katsumi, Y., Moore, M., Berggren, N., de Gelder, B., Derakshan, N., . . Okon-Singer, H. (2019). Neural Correlates of Emotion-Attention Interactions: From Perception, Learning and Memory to Individual Differences and Training Interventions. Neuroscience Biobehavioral Reviews, 2.

Eser, Z., Isin, F. B., \& Tolon, M. (2011). Perceptions of marketing academics, neurologists, and marketing professionals about neuromarketing. Journal of Marketing Management, 27(78), 854-868.

Fisher, C., Chin, L., \& Klitzman, R. (2010). Defining neuromarketing: Practices and professional challenges. Harvard Review of Psychiatry, 18(4), 230-237.

Fortunato, V. C. R., Giraldi, J. D. M. E., \& Oliveira, J. H. C. D. (2014). A review of studies on neuromarketing: Practical results, techniques, contributions and limitations. Journal of Management Research, 6(2), 201-221.

Frijda, N. H. (1987). Emotion, cognitive structure, and action tendency. Cognition and emotion, $1(2), 115-143$.

Fugate, D. L. (2007). Neuromarketing: a layman's look at neuroscience and its potential application to marketing practice. Journal of Consumer Marketing, 24(7), 385-394.

Gani, M., Reza, S., \& Rabi, M. (2015). Neuromarketing: methodologies of marketing science. Paper presented at the Proceedings of The 3rd International Conference On Advances in Economics, Management and Social Study.

Hammond, M. (2006). Evolutionary theory and emotions. In Handbook of the Sociology of Emotions (pp. 368-385): Springer.

$\mathrm{Hu}, \mathrm{Z}$., \& Nasiry, J. (2018). Are markets with loss-averse consumers more sensitive to losses? Management Science, 64(3), 1384-1395.

Isa, S. M., Mansor, A. A., \& Razali, K. (2019). Ethics in Neuromarketing and its Implications on Business to Stay Vigilant. KnE Social Sciences, 687-711-687-711.

Javor, A., Koller, M., Lee, N., Chamberlain, L., \& Ransmayr, G. (2013). Neuromarketing and consumer neuroscience: contributions to neurology. BMC neurology, 13(1), 13.

Jordão, I. L. D. S., Souza, M. T. D., Oliveira, J. H. C. D., \& Giraldi, J. D. M. E. (2017). Neuromarketing applied to consumer behaviour: an integrative literature review between 2010 and 2015 . International Journal of Business Forecasting and Marketing Intelligence, 3(3), 270-288.

Kenning, P., \& Linzmajer, M. (2011). Consumer neuroscience: an overview of an emerging discipline with implications for consumer policy. Journal für Verbraucherschutz und Lebensmittelsicherheit, 6(1), 111-125. 
Koenigs, M., \& Tranel, D. (2008). Prefrontal cortex damage abolishes brand-cued changes in cola preference. Social Cognitive and Affective Neuroscience, 3(1), 1-6.

Lazarus, R. S. (2006). Stress and emotion: A new synthesis: Springer Publishing Company.

LeDoux, J. E., \& Brown, R. (2017). A higher-order theory of emotional consciousness. Proceedings of the National Academy of Sciences, 114(10).

Lim, W. M. (2018). Demystifying neuromarketing. Journal of Business Research, 91, 205-220.

Lindquist, K. A., Satpute, A. B., Wager, T. D., Weber, J., \& Barrett, L. F. (2015). The brain basis of positive and negative affect: evidence from a meta-analysis of the human neuroimaging literature. Cerebral Cortex, 26(5), 1910-1922.

Maren, S., Phan, K. L., \& Liberzon, I. (2013). The contextual brain: implications for fear conditioning, extinction and psychopathology. Nature Reviews Neuroscience, 14(6), 417428.

McClure, S. M., Li, J., Tomlin, D., Cypert, K. S., Montague, L. M., \& Montague, P. R. (2004). Neural correlates of behavioral preference for culturally familiar drinks. Neuron, 44(2), 379-387.

Mileti, A., Guido, G., \& Prete, M. I. (2016). Nanomarketing: a new frontier for neuromarketing. Psychology \& Marketing, 33(8), 664-674.

Modica, E., Rossi, D., Cartocci, G., Perrotta, D., Di Feo, P., Mancini, M., . . Babiloni, F. (2018). Neurophysiological Profile of Antismoking Campaigns. Computational Intelligence and Neuroscience, 5(3), 01-11.

Montazeribarforoushi, S., Keshavarzsaleh, A., \& Ramsøy, T. Z. (2017). On the hierarchy of choice: An applied neuroscience perspective on the AIDA model. Cogent Psychology, 4(1), 1363343.

Moreno, B., \& Arteaga, G. (2012). Violation of ethical principles in clinical research. Influences and possible solutions for Latin America. Bmc Medical Ethics, 13(1), 1-4.

Morin, C. (2011). Neuromarketing: The new science of consumer behavior. Society, 48(2), 131135.

Motzkin, J. C., Philippi, C. L., Wolf, R. C., Baskaya, M. K., \& Koenigs, M. (2015). Ventromedial prefrontal cortex is critical for the regulation of amygdala activity in humans. Biological Psychiatry, 77(3), 276-284.

Murphy, E., Illes, J., \& Reiner, P. (2008). Neuroethics of neuromarketing. Journal of Consumer Behaviour, 7(4), 293-302.

Nemorin, S., \& Gandy, O. (2017). Exploring neuromarketing and its reliance on remote sensing: Social and ethical concerns. International Journal of Communication, 11(3), 4824-4844.

Orzan, G., Zara, I., \& Purcarea, V. (2012). Neuromarketing techniques in pharmaceutical drugs advertising. A discussion and agenda for future research. Journal of medicine and life, 5(4), 428-432.

Page, G. (2012). Scientific realism: What neuromarketing can and can't tell us about consumers. International Journal of Market Research, 54(2), 287-290.

Pessoa, L. (2009). How do emotion and motivation direct executive control? , 13(4), 160-166.

Pessoa, L. (2013). The cognitive-emotional brain: From interactions to integration: MIT press.

Pop, N., Dabija, D., \& Iorga, A. (2014). Ethical responsibility of neuromarketing companies in harnessing the market research: A global exploratory approach. Amfiteatru Economic, 16(35), 26-40. 
Posner, J., Russell, J. A., \& Peterson, B. S. (2005). The circumplex model of affect: An integrative approach to affective neuroscience, cognitive development, and psychopathology. Development and Psychopathology, 17(3), 715.

Ramsoy, T. (2014). An Introduction to Consumer Neuroscience \& Neuromarketing Retrieved from https://www.coursera.org/learn/neuromarketing/lecture/FTWBU/introduction-to-thiscourse

Ramsoy, T. Z. (2015). Introduction to neuromarketing \& consumer neuroscience: Neurons Inc.

Rilling, J. K., King-Casas, B., \& Sanfey, A. G. (2008). The neurobiology of social decision-making. Current opinion in neurobiology, 18(2), 159-165.

Scherer, K. R. (2005). What are emotions? And how can they be measured? Social science information, 44(4), 695-729.

School, C. B. (2019). The Neuromarketing Toolbox. Retrieved from https://www.coursera.org/learn/neuromarketing-toolbox/home/week/5

Sebastian, V. (2014). Neuromarketing and evaluation of cognitive and emotional responses of consumers to marketing stimuli. Procedia Social Behavioral Sciences, 127(2), 753-757.

Sebastian, V. (2014). New directions in understanding the decision-making process: neuroeconomics and neuromarketing. In M. Chraif, C. Vasile, \& M. Anitei (Eds.), International Conference Psychology and the Realities of the Contemporary World (Vol. 127, pp. 758-762). Amsterdam: Elsevier Science Bv.

Senior, C., \& Lee, N. (2013). The state of the art in organizational cognitive neuroscience: the therapeutic gap and possible implications for clinical practice. Frontiers in Human Neuroscience, 7, 5. doi:10.3389/fnhum.2013.00808

Shafer, A., Iordan, A., Cabeza, R., \& Dolcos, F. J. J. (2011). Brain imaging investigation of the memory-enhancing effect of emotion. (51), e2433.

Sirico Jr, L. J. (2016). The Trial Lawyer and the Reptilian Brain: A Critique. Clev. St. L. Rev., 65, 411.

Spielman, R. M., Dumper, K., Jenkins, W., Lovett, M., \& Perlmutter, M. (2014). Psychology.

Stanton, S., Armstrong, W., \& Huettel, S. (2017). Neuromarketing: Ethical implications of its use and potential misuse. Journal of Business Ethics, 144(4), 799-811.

Thagard, P. (2019). Brain-Mind: From Neurons to Consciousness and Creativity (Treatise on Mind and Society): Oxford University Press.

Tranel, D., \& Damasio, H. (1991). Somatic Markers and the Guidance of Behaviour: Theory and Preliminary Testing. In: Oxford University Press New York.

Ulman, Y. I., Cakar, T., \& Yildiz, G. (2015). Ethical Issues in Neuromarketing: I consume, therefore I am. Science and Engineering Ethics, 21(5), 1271-1284. doi:10.1007/s11948-014-9581-5

Venkatraman, V., Dimoka, A., Pavlou, P. A., Vo, K., Hampton, W., Bollinger, B., . . Winer, R. S. (2015). Predicting advertising success beyond traditional measures: New insights from neurophysiological methods and market response modeling. Journal of Marketing Research, 52(4), 436-452.

Vermaak, M., \& de Klerk, H. M. (2017). Fitting room or selling room? Millennial female consumers' dressing room experiences. International Journal of Consumer Studies, 41(1), 11-18.

Wang, Y., \& Minor, M. (2008). Validity, reliability, and applicability of psychophysiological techniques in marketing research. Psychology \& Marketing, 25(2), 197-232. 
INTERNATIONAL JOURNAL OF ACADEMIC RESEARCH ECONOMICS AND MANAGEMENT SCIENCES Vol. 10, No. 2, 2021, E-ISSN: 2226-3624 @ 2021 HRMARS

Zander, T., \& Kothe, C. (2011). Towards passive brain-computer interfaces: applying braincomputer interface technology to human-machine systems in general. Journal of neural engineering, 8(2), 1-5.

Zurawicki, L. (2010). Neuromarketing: Exploring the brain of the consumer: Springer Science \& Business Media. 
Table

Table 1. Taxonomy of Human Brain.

\begin{tabular}{|c|c|}
\hline Elements & Locations, Components, Functions, and Contributions \\
\hline \multirow{4}{*}{$\begin{array}{l}\text { Neo-Cortex Brain } \\
\text { (Rational/ } \\
\text { Conscious Brain) }\end{array}$} & $\begin{array}{l}\text { Location: The external layer of the human brain. It covers approximately } \\
\text { the whole of the brain except for the cerebellum and accounts for about } \\
76 \% \text { of the human brain volume (Amthor, 2016). }\end{array}$ \\
\hline & $\begin{array}{l}\text { Components: It includes four lobes, namely, the frontal lobe (FL), parietal } \\
\text { lobe (PL), temporal lobe (TL), and occipital lobe (OL) (Amthor, 2016). }\end{array}$ \\
\hline & $\begin{array}{l}\text { Functions: It responsible for high cognitive functions that distinguish } \\
\text { humans from other mammals, and it is a unique and analytical part of the } \\
\text { human brain which resorts to language and logic to solve problems } \\
\text { (Amthor, 2016). }\end{array}$ \\
\hline & $\begin{array}{l}\text { Contributions: It has primarily contributed to people's memory, } \\
\text { emotions, behaviour, emotional learning, reward, previous experiences, } \\
\text { beliefs, personal values, self-image, and motivation (Gani et al., 2015). } \\
\text { Plus, it creates rational memories conducive to creative thinking (Sirico Jr, } \\
\text { 2016). }\end{array}$ \\
\hline \multirow{4}{*}{$\begin{array}{l}\text { Limbic Brain } \\
\text { (Emotional/ } \\
\text { Subconscious } \\
\text { Brain) }\end{array}$} & $\begin{array}{l}\text { Location: The middle layer of the human brain, it is directly located } \\
\text { underneath the cerebral cortex/Neo-cortex, in other words, located } \\
\text { underneath the OL and the TL (Amthor, 2016). }\end{array}$ \\
\hline & $\begin{array}{l}\text { Components: It consists of several elements, such as Thalamus, } \\
\text { Hypothalamus (HC), Amygdala (AMY), Cingulate Cortex (CC), and Basal } \\
\text { Ganglia (Amthor, 2016). }\end{array}$ \\
\hline & $\begin{array}{l}\text { Functions: It is associated with emotional, social life and seat of } \\
\text { judgments and information intuition (Amthor, 2016). }\end{array}$ \\
\hline & $\begin{array}{l}\text { Contributions: It has contributed to personal and related behavioural } \\
\text { responses (e.g., sexual behaviour, fighting or fleeing), attention, feelings, } \\
\text { memory, immunity, and hormonal balance (Sirico Jr, 2016). }\end{array}$ \\
\hline \multirow{4}{*}{$\begin{array}{l}\text { Reptilian Brain } \\
\text { (Primitive/ } \\
\text { Unconscious } \\
\text { Brain) }\end{array}$} & $\begin{array}{l}\text { Location: The distal layer of the human brain, is directly located } \\
\text { underneath the Limbic layer (Amthor, 2016). }\end{array}$ \\
\hline & $\begin{array}{l}\text { Components: It consists of the Cerebellum and the Spinal Cord (Amthor, } \\
\text { 2016). }\end{array}$ \\
\hline & $\begin{array}{l}\text { Functions: This part of the brain is related to the basic functions that must } \\
\text { be performed to sustain life (e.g., circulation, body temperature, heart } \\
\text { rate, balance, and breathing) (Gani et al., 2015). }\end{array}$ \\
\hline & $\begin{array}{l}\text { Contributions: It is contributed to a quick decision-maker, such as but not } \\
\text { limited to, what strategy must be taken very quickly as wait, withdrawal, } \\
\text { defense when exposed to threats to guarantee the basic needs of human } \\
\text { satisfaction and safety (Sirico Jr, 2016). }\end{array}$ \\
\hline
\end{tabular}


INTERNATIONAL JOURNAL OF ACADEMIC RESEARCH ECONOMICS AND MANAGEMENT SCIENCES Vol. 10, No. 2, 2021, E-ISSN: 2226-3624 @ 2021 HRMARS

\section{Figures}

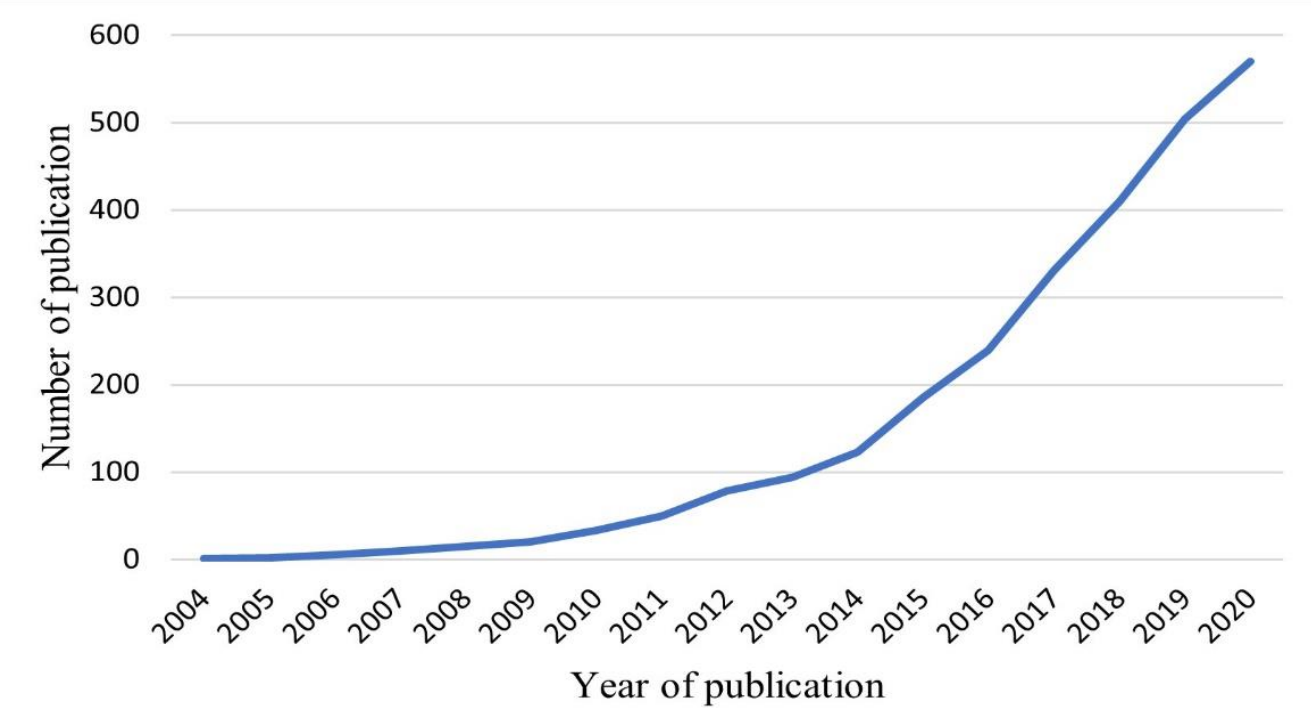

Figure 1. The Number of Neuromarketing Publications from 2002 to 2018. Source: Web of Science database.

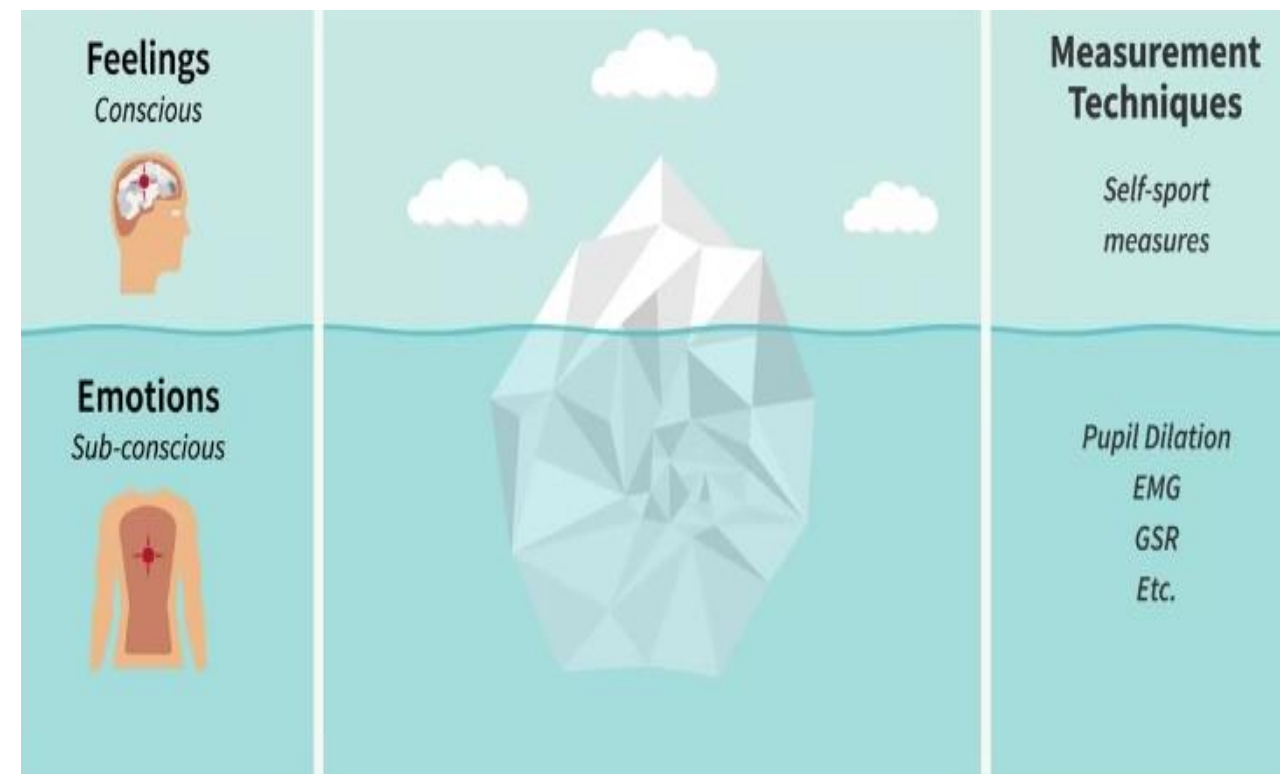

Figure 2. The Nature of Emotions and Feelings (School, Dec 27, 2019). 


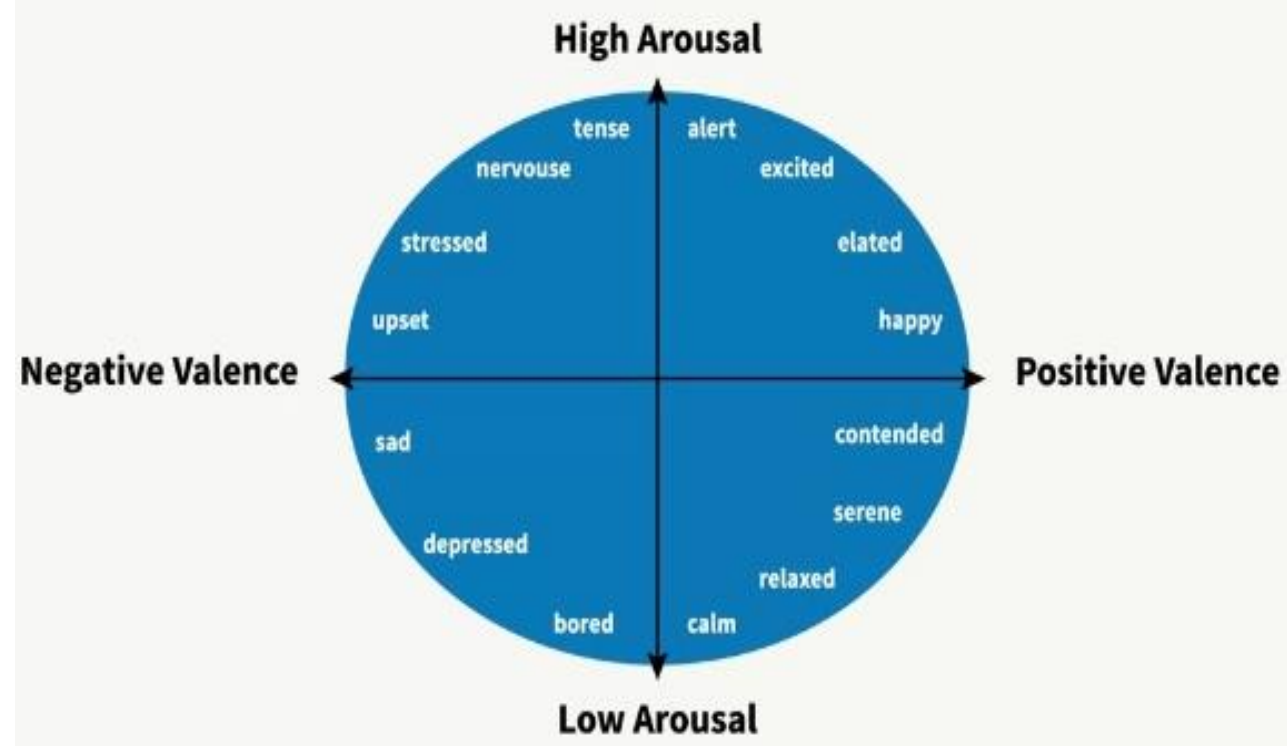

Figure 3. The Circumplex Model of Emotions (Posner et al., 2005).

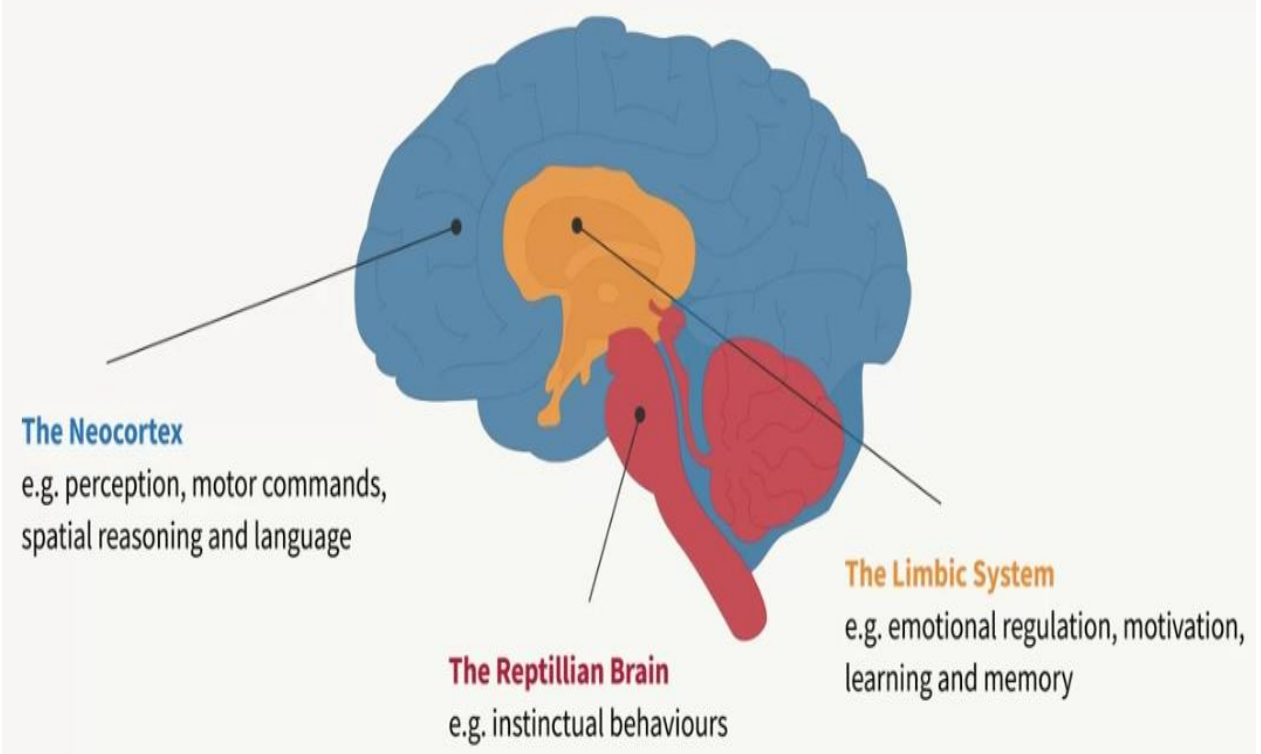

Figure 4. The Longitudinal View of the Brain (School, Dec 27, 2019). 
INTERNATIONAL JOURNAL OF ACADEMIC RESEARCH ECONOMICS AND MANAGEMENT SCIENCES Vol. 10, No. 2, 2021, E-ISSN: $2226-3624$ @ 2021 HRMARS
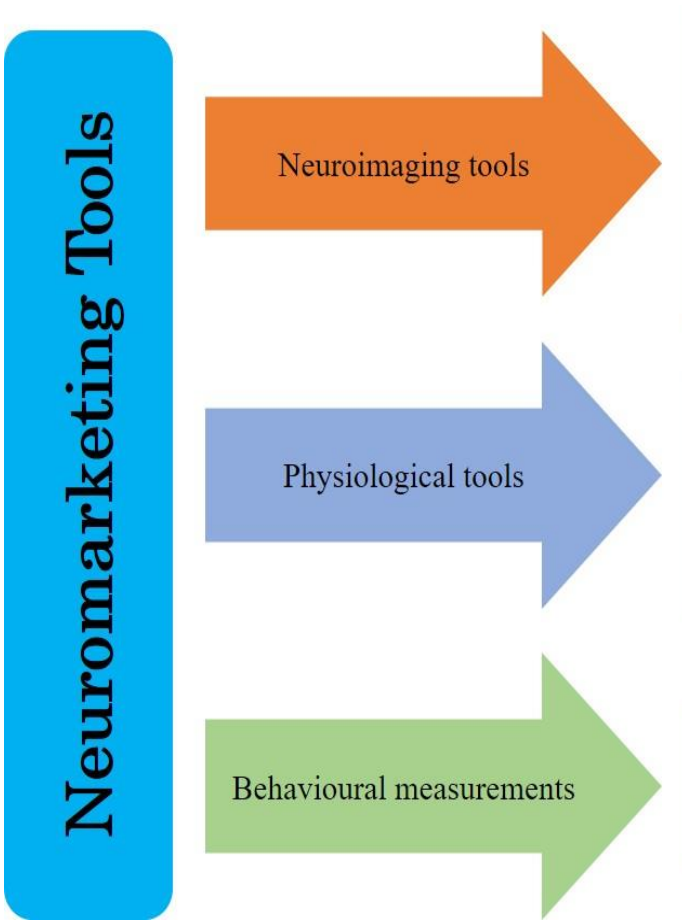

Functional Magnetic Resonance Imaging (fMRI)

$\checkmark$ Positron Emission Tomography (PET)

$\checkmark$ Functional Infrared Spectroscopy (fNIRS)

$\checkmark$ Electroencephalography (EEG)

$\checkmark$ Magnetoencephalography (MEG)

$\checkmark$ Steady-Skin Topography (SST)

$\checkmark$ Single Photon Emission Tomography (SPET)

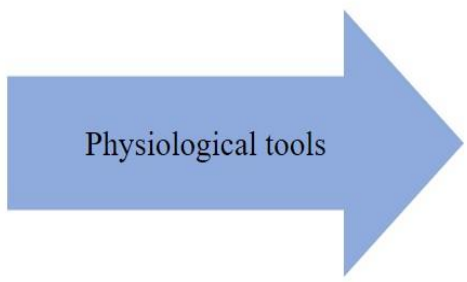

$\checkmark$ Eye-Tracking (ET)

$\checkmark$ Facial Expression Recognition

$\checkmark \quad$ Skin Galvanic Response (SGR)

$\checkmark$ Electrocardiogram (ECG)

Behavioural measurements

Self-Report (e.g., surveys, focus groups, interviews, and observation)

Figure 5. Classification of Neuromarketing tools.

Source: Own illustration 